\title{
DESIGN OF WEB BASED DYNAMIC ASSESSMENT SYSTEM FOR SOLVING TWO SIGMA PROBLEM
}

\author{
Arif Tuluk $^{1}$, Muhittin Şahin ${ }^{2}$ and Halil Yurdugül ${ }^{1}$ \\ ${ }^{1}$ Hacettepe University, Turkey \\ ${ }^{2}$ Ege University, Turkey
}

\begin{abstract}
In 1984 Benjamin Bloom stated that one-to-one tutorial support increased students' achievement by two standard deviations (two sigma problem). In the literature for solving two sigma problem (in order to increase student achievement), many systems were developed as intelligent tutoring systems, adaptive hypermedia systems, recommender systems and etc. In addition to this, it can be said that dynamic assessment increases the students' achievement. Because one of the main objectives of the dynamic assessment is to improve the performance of learners by providing instructional aids with assessment tasks. Within the scope of this research, a web-based dynamic assessment system was designed and developed. Then, the effectiveness of the system tested with actual users. One group pretest-posttest design was used. A total of 322 secondary school $5^{\text {th }}$-grade students participated in this study. The findings were discussed in the context of two sigma problems. According to the findings, it can be said that the web-based dynamic assessment system increases student achievement approximately two standard deviations.
\end{abstract}

\section{KEYWORDS}

Two Sigma Problem, Dynamic Assessment, Web-Based Dynamic Assessment System

\section{INTRODUCTION}

Bloom (1984) stated that one-to-one tutorial support increased students' achievement by two standard deviations. In this context from past to present, many environments were designed and developed in order to support the students. At the same time, this perspective is closely related to "The Zone of Proximal Development-ZPD" in Vygotsky's theory of social constructivism. ZPD is expressed as the gap between what the student can do without help and what he can do with help (Bodrova \& Leong, 1996; Vygotsky, 1978). It can be said that one of the alternatives for filling this gap is dynamic assessment. Because one of the main objectives of the dynamic assessment is to improve the performance of learners by providing instructional aids with assessment tasks. In this context, the feature that separates dynamic assessment from the static assessment can be explained by the concept of feedback. In the dynamic assessment, feedback is based on the performance of an assessment task; rather than cognitive, affective and motivational information about the performance of the students. In recent years, web-based assessment environments have also increased. Within the scope of this research, a web-based dynamic assessment system was designed and students were provided with a learning experience. As a result of this experience, the development of learning was discussed within the framework of two sigma problems. In this context this study includes, firstly, web-based dynamic assessment, the web-based dynamic assessment system presented to the students and finally the findings of the experimental research.

\subsection{Dynamic Web Based Assessment}

The development of dynamic assessment was greatly influenced by L.S. Vygotsky (Haywood, et al., 1990; Allal \& Ducrey, 2000). Vygotsky (1978) emphasized that social context plays a role in children's learning and development. Vygotsky proposed the theory of "Zone of Proximal Development (ZPD)" to describe the difference between children's performance without the help of adults and their more competent peers (Vygotsky, 1978). The ZPD represents the learning potential of children. By interacting with adults or more 
competent peers, children's learning potentials can be revealed and learning activities can be improved. Dynamic assessment is an interactive assessment commonly given as "test-teach-retest" (Haywood \& Lidz, 2007). In the dynamic assessment, individuals are given the opportunity to learn (Bransford, et al., 1987) and are included in the teaching and feedback testing process (Elliott, 2003). In educational psychology, the traditional use of dynamic assessment is to help classify examiners, select specific forms of mediation or training, and predict their true abilities (Elliott, 2003). However, Elliott (2003), Haywood and Lidz (2007) and Poehner (2008) stated that dynamic assessment can be integrated into school curriculum and education to assist educators and support learners' learning. This study attempts to combine two main educational features of dynamic assessment and, as a result, to suggest "assessment as a learning and teaching strategy". In other words, this idea means that learning and teaching strategies are structured around a web-based dynamic assessment and seamlessly combined with learning and teaching activities in the web-based dynamic assessment. In the process of web-based dynamic assessment, learning takes place through guidance and instruction provided by the assessment. In this research, a web-based dynamic assessment system has been developed based on the idea of "assessment as a learning and teaching strategy". Trainers are expected to create e-learning environments based on assessment, which will provide students with a more effective learning experience by taking advantage of this system. Trainers can also use this system to integrate the scaffolding assessment process simultaneously.

Sternberg and Grigorenko (2001) stated that there are two types of dynamic assessment as sandwich and cake form. Both formats are implemented as "test-teach-retest". The sandwich format dynamic assessment means that the instruction is held between the pre-test and the post-test, thus forming a sandwich-like process. In the dynamic assessment of cakes, teaching is a response to the answers given to each question by the researchers. In this research, since the assessment is considered as a learning and teaching strategy, cake-like dynamic assessment principles are adopted in designing the web-based dynamic assessment system. The main feature of the dynamic assessment of cakes is the design of successive cues with a progressive set of clues. This design is similar to the "graduated prompt approach" recommended by Campione and Brown $(1985,1987)$. According to Campione and Brown, the clues in the "graduated prompt approach" are presented in a predetermined order, arranged according to their disclosure levels (Bransford, et al., 1987). They start with "general hints" and gradually become "specific hints". General hints provide relatively little specific information about the solution, while a specific hint provides a detailed instruction that students can produce the right answer (Campione \& Brown, 1985, 1987). In this study, the "graduated prompt approach" and the clues provided by the dynamic assessment elements were used to develop the web-based dynamic assessment system. These clues are called instructional guidance (IG) because they are used to guide and teach students. When students answer an item incorrectly, the IGs are progressively learned and learn to find the right answer step by step.

\section{METHOD}

\subsection{Research Design}

Within the scope of the research, pretest-posttest design was employed in quasi-experimental research and used without control group. This design includes a single group and the effectiveness of the application/intervention is determined by the development of pre-test and post-test.

\subsection{Participants}

A total of 322 secondary school $5^{\text {th }}$-grade students participated in the study. These students are located in three different provinces in Turkey to continue their education and training in secondary schools.

\subsection{Web Based Dynamic Assessment System}

Within the scope of this research, an online environment with the idea of dynamic assessment of the cake format proposed by Sternberg and Grigorenko (2001) was developed to design the scaffolding strategies in the web-based dynamic assessment system. If students answer the question correctly, they get an encouraging statement and a score (Figure 1a), if the wrong answers are scaffolding (Figure 1b). 


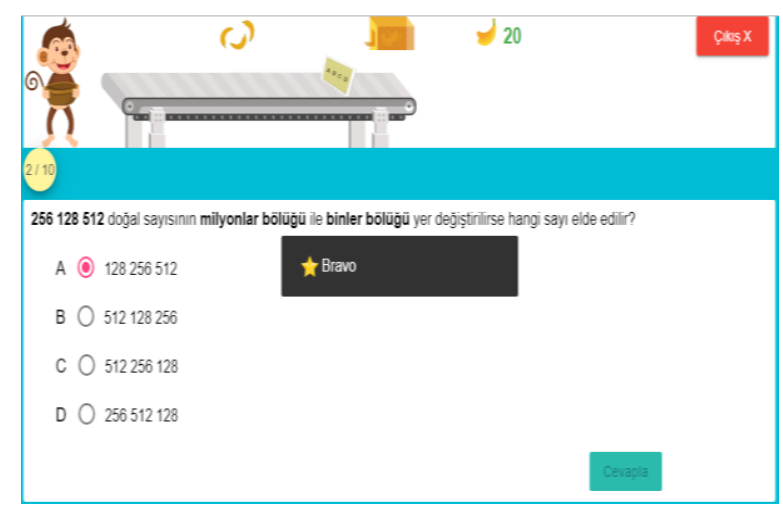

Figure 1a. Screen-shot for correct response

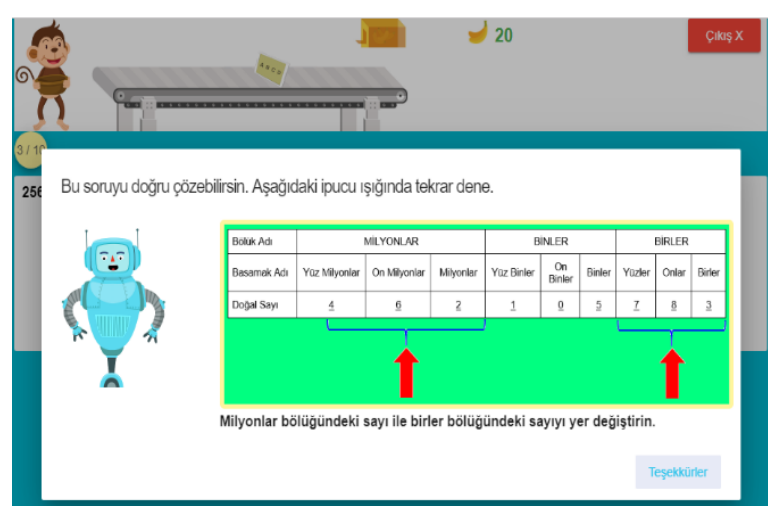

Figure 1b. Screen-shot for the wrong response

As shown in Figure 1b, when students respond incorrectly for the first time to an assessment item, a general scaffolding is offered to the students by the assessment system. Students are asked to answer the same assessment item again after the first IG. When the same assessment item responds incorrectly by the students for the second time, more specific instructional guidance is given by the system. Students who receive the second IG are required to respond to the same assessment item for the third time. If the third time is answered incorrectly, the system is presented by an even more specific IG. As the only item left in the assessment item after the third IG is left, the next assessment item is displayed after showing that the remaining item of the assessment item is correct. Students are expected to use the gains they gained here (IGs) in their next assessment tasks.

\subsection{Data Collection Tools}

In order to observe the development of the students, success tests developed by the researchers were applied for two different gains. Both pre-test and post-test were applied for each gain.

\subsection{Data Analysis}

In order to determine the development of the students, Paired Sample T-Test was employed. Additional calculations were utilized for solving two sigma problem.

\section{FINDINGS}

Within the scope of this research, paired sample t-test was used for each gain in order to determine the web-based dynamic assessment system achievement. The results of the analysis for the first gain are presented in Table 1.

Table 1. Results of Paired Sample T-Test for Gain 1

\begin{tabular}{llllll}
\hline & $\mathrm{n}$ & $\mathrm{X}_{\text {ave }}$ & $\mathrm{df}$ & $\mathrm{t}$ & $\mathrm{p}$ \\
\hline Pretest & 322 & 5,88 & 321 & $-56,05$ & 0,00 \\
Posttest & 322 & 7,63 & & & \\
\hline $\mathrm{p}<0,01$ & & & & &
\end{tabular}

As can be seen in Table 1, it can be said that the achievement of students has increased statistically significantly. The results of the analysis for the first gain are presented in Table 2. 
Table 2. Results of Paired Sample T-Test for Gain 2

\begin{tabular}{llllll}
\hline & $\mathrm{n}$ & $\mathrm{X}_{\text {ave }}$ & $\mathrm{df}$ & $\mathrm{t}$ & $\mathrm{p}$ \\
\hline Pretest & 322 & 4,36 & 321 & $-54,06$ & 0,00 \\
Posttest & 322 & 5,84 & & & \\
\hline $\mathrm{p}<0,01$ & & & & &
\end{tabular}

As shown in Table 2, it can be said that the achievement of students has increased statistically. According to the findings, it can be said that the developed system increases the students' achievements by approximately two standard deviations.

\section{CONCLUSION}

One-to-one tutorial support enhances two standard deviations of student achievement (Bloom, 1984). This situation is also closely related to the ZPD established by Vygotsky (Vygotsky, 1978). Because ZPD is the difference between what an individual can do with help and without help. Within the scope of this research, a web-based dynamic assessment system has been designed and developed in order to solve two sigma problem. Within the scope of this research, an online environment with the idea of dynamic assessment of the cake format proposed by Sternberg and Grigorenko (2001) was developed to design the scaffolding strategies in the web-based dynamic assessment system. In order to test the success of the developed system, students have experienced two different gains in the system. Then, paired sample t-test was performed. According to the findings, it was found that the system was increased students' achievement approximately two standard deviations. Based on these results, it is thought that the web-based dynamic assessment system may offer a solution for two sigma problem.

\section{REFERENCES}

Allal, L., Ducrey, G.P. (2000). Assessment of-or in-the zone of proximal development. Learning and Instruction, 10(2), 137-152. https://doi.org/10.1016/S0959-4752(99)00025-0.

Bloom, B.S. (1984). The 2 sigma problem: The search for methods of group instruction as effective as one-to-one tutoring. Educational Researcher, 13(6), 4-16.

Bodrova, E., \& Leong, D. J. (1996). Tools of the mind: The Vygotskian approach to early childhood education. Englewood Cliffs, NJ: Merrill/Prentice Hall.

Bransford, J. D., Delclos, V., Vye, N., Bums, S., \& Hasselbring, T. (1987). Approaches to dynamic assessment: Issues, data and future directions. In C. Lidz (Ed.), Dynamic assessment: An interactional approach to evaluating learning potentials. New York: Guilford Press, 479-495.

Bransford, J. D., Brown, A. L., \& Cocking, R. R. (2000). How people learn: Brain, mind, experience and school. Expanded Edition, Washington, DC: National Academy Press. http://nap.edu/9853.

Campione, J. C., \& Brown, A. L. (1985). Dynamic assessment: One approach and some initial data. (Technical report No. 361). Bethesda, MD: National Institute of Child Health and Human Development; National Institute of Education.

Campione, J. C., \& Brown, A. L. (1987). Linking dynamic assessment with school achievement. In C. S. Lidz (Ed.), Dynamic assessment: An international approach to evaluating learning potential. The Guilford Press, New York, $82-115$.

Elliott, J. G. (2003). Dynamic assessment in educational settings: Realizing potential. Educational Review, 55, 15-32.

Haywood, H. C., Brown, A. L., \& Wingenfeld, S. (1990). Dynamic approaches to psycho-educational assessment. School Psychology Review, 19, 411-422.

Haywood, H. C., Lidz, C. S. (2007). Dynamic assessment in practice. Clinical and educational applications. Cambridge University Press, New York.

Poehner, M. E. (2008). Dynamic assessment: A Vygotskian approach to understanding and promoting L2 development. Springer, New York.

Sternberg, R. J., \& Grigorenko, E. L. (2001). All testing is dynamic testing. Issues in Education, 7, 137-170.

Vygotsky, L. S. (1978). Mind and society: The development of higher mental processes. Cambridge, MA: Harvard University Press. (Original work published in 1930, 1933, 1935). 